\title{
Distributions of Temporal Metaphors in Japanese
}

\author{
Kohei Suzuki \\ Mie University, Mie, Japan
}

\begin{abstract}
In the conceptual metaphor theory, it has been common to assume at least two metaphors where concepts of Time are structured through concepts of Space; Time-moving metaphor and Ego-moving metaphor. Several researchers carried out quantitative studies and revealed that languages have preferences on these Temporal metaphors: Ego-moving metaphor is more preferable in English and Chinese. This paper conducted a corpus-based research on the distributions of dual Temporal metaphors. This study observed Time-moving metaphor is more frequent in Japanese, contrary to the prediction from English and Chinese. This study clearly shows that most motion verbs have skewed distributions between Time-moving meaning and Ego-moving meaning and few verbs have "dual" usage at all in Japanese. In addition, this study's data indicate Time-moving metaphor and Ego-moving metaphor are not mere variants of each other, but each metaphor has peculiar and complicated constraints on its usage.
\end{abstract}

Keywords: dual Temporal metaphors, Time-moving metaphor, Ego-moving metaphor, corpus, frequency

\section{Introduction}

This paper demonstrates a corpus-based approach to the investigation of metaphor research. This paper compares the frequencies of dual Temporal metaphors and suggests Japanese native speakers prefer Time-moving metaphor more.

In the conceptual metaphor theory, it has been common to assume two metaphors where concepts of Time are structured through concepts of Space: Time-moving metaphor and Ego-moving metaphor (Kövecses, 2002; Lakoff, 1993; Lakoff \& Johnson, 1999). ${ }^{1}$ The followings are examples of these metaphors.

Example (1) a. We're fast approaching Christmas.

b. Christmas is fast approaching.

Example (2) a. We're coming up on Christmas.

b. Christmas is coming up on us.

In each pair, (1a) and (2a) describes Time as a Location on a landscape, and the person, instantiated as "we", moves in the time course. On the other hand, Time is moving past the person from front to back while the person remains stationary in (1b) and (2b). This study calls these metaphors Ego-moving metaphor and Time-moving metaphor respectively. Notice, just the same verbs are used in both (1a) and (1b) and, (2a) and (2b). The point is that these metaphorical expressions have dual roles in English.

According to Lakoff and Johnson (1999) each metaphor has the following composite mapping.

Kohei Suzuki, lecturer, Ph.D., Liberal Arts Center, Mie University.

1 Some researchers (Moore, 2000; Núñez, Motz, \& Teuscher, 2006; Núñez \& Sweetser, 2006) suggested the third metaphor, Ego-observing metaphor. However, describing the detailed distribution of this metaphor goes beyond the scope of this study. 
(1) Mappings of Ego-moving metaphor

The Location Of The Observer

The Space In Front Of the Observer

The Space Behind The Observer

Locations On Observer's Path Of Motion

The Motion Of The Observer

The Distance Moved By The Observer

(2) Mappings of Time-moving metaphor

The Location Of The Observer

The Space In Front Of the Observer

The Space Behind The Observer

Objects $\rightarrow$ The Present

$\rightarrow$ The Future

$\rightarrow$ The Past

$\rightarrow$ Times

$\rightarrow$ The "Passage" Of Time

$\rightarrow$ The Amount Of Time "Passed"

$\rightarrow$ The Present

$\rightarrow$ The Future

$\rightarrow$ The Past

$\rightarrow$ Times

While these metaphors have common mappings, these metaphors are conflicting each other in other mappings. But Lakoff and Johnson (1999) suggested, "these are actually minimally differing variants of one another. In short, they are figure-ground reversals of one another" (p. 149). Though their analysis depends on detailed descriptions of metaphorical expressions, they neither conducted any quantitative research nor mentioned the cross linguistic differences of the preference between two metaphors.

Several researchers carried out quantitative studies and revealed that languages have preferences on these Temporal metaphors. Gentner, Imai, and Boroditsky (2002) conducted an experiment-based research on English native speakers and suggested their subjects took longer time to respond to sentences that include the Time-moving metaphor than Ego-moving metaphor. Their result signaled that the Ego-moving metaphor is easier or more natural for English speakers. May and Shelley (2007) conducted the same experimental research on Chinese native speakers and suggested: "Chinese native speakers... process Chinese ego-moving metaphors better, for they are the natural expressions which accord to people's cognitive process" (p. 180).

These experimental researches clearly showed that English and Chinese native speakers prefer Ego-moving metaphor more. Japanese seems to have a different preference on this matter.

Time-moving metaphor:

Example (3) shimekiri-ga chikadsuite-ki-ta deadline-Nom come closer-come-pst

"The deadline is coming closer."

Example (4) 3-nen-no tsukihi-ga nagare-ta

3-year-Gen years-Nom flow-pst

"Three years have passed."

Ego-moving metaphor:

Example (3)' ?shimekiri-ni chikadsuite-ki-ta

deadline-Obl come closer-come-pst

Example (4) $* 3$-nenn-no tsukihi-ni nagare-ta

3-year-Gen year-Obl flow-pst 
Example (4)"*mirai-ni mukatte nagare-ta

future-Obl toward flow-pst

In Examples (3)-(4), sentences including Time-moving metaphor are grammatical, whereas their corresponding examples are odd or totally incomprehensible. Further, many of Japanese motion verbs do not have dual roles as this paper saw in Examples (1)-(2).

\section{Methodology}

This study demonstrates a corpus-based approach to explore how Japanese speakers use Time-moving and Ego-moving metaphors. This study supposes if the Time-moving metaphor is easier and more natural for Japanese speakers, corpus data will include more Time-moving metaphors than Ego-moving metaphors.

This study utilizes Balanced Corpus of Contemporary Written Japanese (BCCWJ) which includes 100 million words. A concordancer is chunagon which is a standard concordancer for retrieving BCCWJ. This study retrieves the co-occurrences of three time expressions, kako (past), mirai (future), and jikan (time), and 51 Japanese motion verbs. The distance between two words is configured within 10 words. All collocates are manually classified on the basis of whether the expression is produced by Ego-moving metaphor or Time-moving metaphor. There are 1,418 examples that contain Temporal metaphor.

This study chooses 51 Japanese motion verbs by depending on Matsumoto (1997). ${ }^{2}$ As Figure 1 shows, motion verbs are classified into three classes: path verbs incorporating direction (direction-path verbs), path verbs incorporating ground (ground-path verbs), and manner verbs.

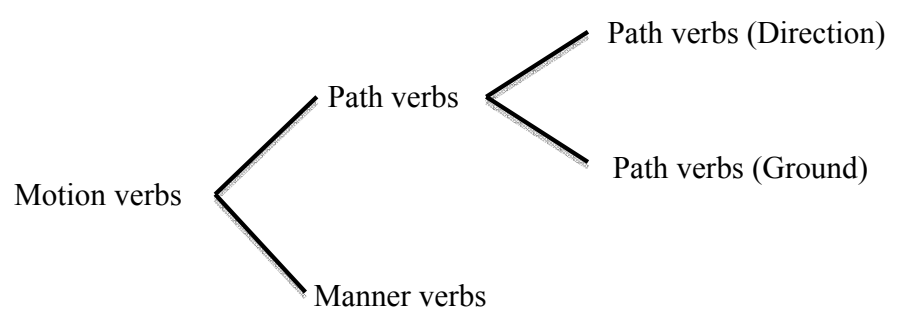

Figure 1. Classification of motion verbs.

Table 1 shows the verbs of each verb class respectively. Please note Japanese has only 13 manner verbs, while having 38 path verbs in total ( 15 direction-path verbs and 23 ground-path verbs). This inequality arises because Japanese is classified as a Verb-framed language and Verb-framed languages encode path of motion more extensively (Slobin, 2004; Talmy, 1991).

Of course, not all motion verbs are used metaphorically. On this matter, Özçalışkan (2003, 2004, 2005) suggested in her seminal studies that to encode metaphorical motion events, verb-framed languages prefer using path verbs with an optional manner adjunct and satellite-framed languages using manner verbs. If she is on the right track, Japanese, a verb-framed language, uses path verbs metaphorically more often than manner verbs. This prediction leads to a further hypothesis: Japanese prefers to describe Time by utilizing path verbs in Time-moving metaphor sense the most.

\footnotetext{
${ }^{2}$ This study adds five verbs to Matsumoto's work because of their frequencies. Five verbs are zenshin-suru (proceed), kotai-suru (retrocede), yatte-kuru (come), chika-yoru (arrive), and chika-dsuku (close up). zenshin-suru (proceed) and kotai-suru (retrocede) are words of Chinese origin and other verbs are compound verbs.
} 
Table 1

List of Targeted Motion Verbs in the Study

\begin{tabular}{llc}
\hline Verb type & Verbs & Total \\
\hline Path (direction) & $\begin{array}{l}\text { iku (go), kuru (come), susumu (move forward), yatte-kuru (come), noboru (climb up), kudaru } \\
\text { (descend), agaru (go up), sagaru (go down), oriru (descend), ochiru (fall down), shizumu (sink), }\end{array}$ & 15 \\
& modoru (return), kaeru (go back), zenshin-suru (proceed), kotai-suru (retrocede) & \\
Path (ground) & $\begin{array}{l}\text { koeru (cross over), wataru (go across), sugiru (pass), meguru (go around), hairu (enter), itaru } \\
\text { (reach), saru (leave), hanareru (get away), syuppatsu-suru (start off), chikadsuku (come close), }\end{array}$ & 23 \\
& $\begin{array}{l}\text { toru (go through), nukeru (drop out of), yokogiru (traverse), magaru (turn), kuguru (go through } \\
\text { under), mawaru (birl), yoru (draw along), tsuuka-suru (overpass), deru (exit), tassuru (come at), }\end{array}$ \\
& $\begin{array}{l}\text { tsuku (arrive), tocyaku-suru (arrive), chikayoru (close up) } \\
\text { Manner verbs (waku (walk), hashiru (run), kakeru (canter/run), hau (worm), suberu (glide), korogaru (roll), }\end{array}$ & 13 \\
& $\begin{array}{l}\text { haneru (jump), mau (flutter), oyogu (swim), tobu (fly), moguru (dive in the deep), nagareru } \\
\text { (flow), isogu (hustle) }\end{array}$ \\
\hline
\end{tabular}

\section{Results and Discussions}

\section{Direction-Path Verbs}

From this section, this paper will look into the results of each verb class in order. The first verb class is direction-path verbs. (5)-(7) are the typical examples of this verb class.

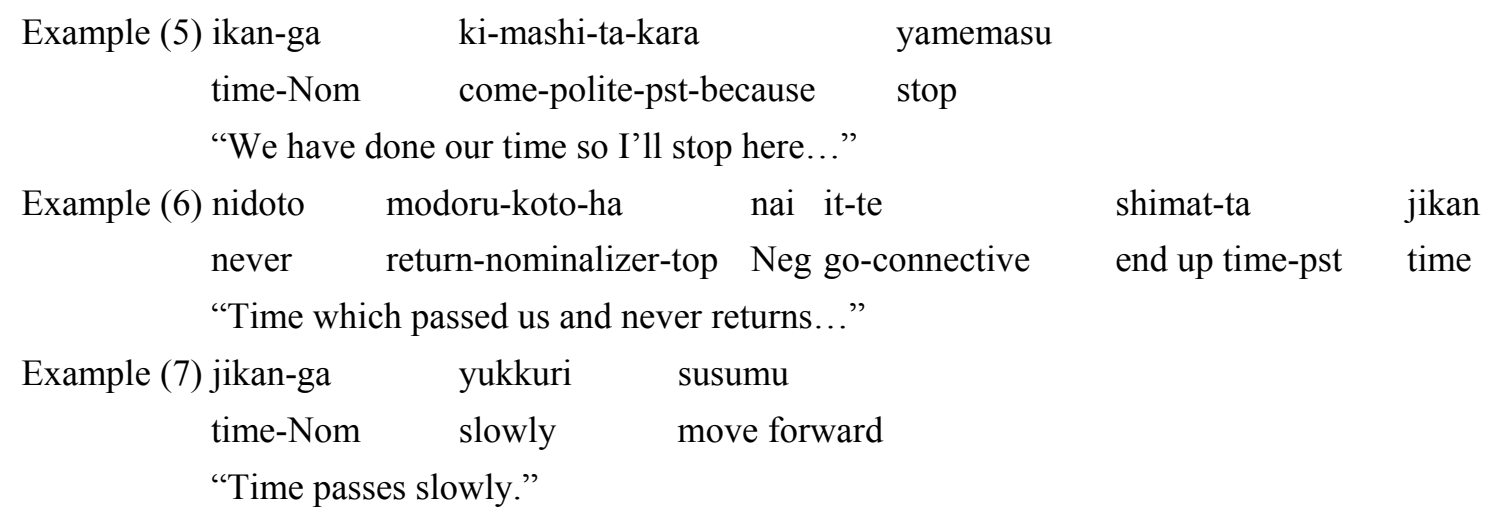

In all of these examples, time is coming from ahead and passed the person: the instances of Time-moving metaphor.

As Table 2 shows, first of all, only four verbs are used as metaphorical expressions of Time. Second, Japanese uses only one-dimensional motion verbs for Temporal metaphor. In other words, not all of the verbs describing the movement in altitude are used metaphorically. Third, Time-moving metaphor outnumbers Ego-moving metaphor in every verb in this verb class. Rather, only one verb, susumu (move forward), is the instance of Ego-moving metaphor-other verbs do not have dual roles in Temporal metaphor.

Table 2

Frequencies of Direction-Path Verbs in Each Temporal Metaphor

\begin{tabular}{lllll}
\hline & Time-moving & Ego-moving & Others and not decided & Sum \\
\hline kuru "come" & 198 & 0 & 1 & 199 \\
susumu "move forward" & 32 & 7 & 0 & 39 \\
yatte-kuru "come" & 16 & 0 & 0 & 16 \\
iku "go" & 1 & 0 & 1 & 2 \\
\hline Sum & 247 & 7 & 2 & 256 \\
\hline
\end{tabular}


Among direcition-path verbs, only susumu (move forward) has dual roles, but this verb has a peculiar preference when it is used in Ego-moving sense.

\begin{tabular}{|c|c|c|c|}
\hline $\begin{array}{l}\text { Example (8) mirai-ni } \\
\text { future-to }\end{array}$ & $\begin{array}{l}\text { mukatte } \\
\text { toward }\end{array}$ & $\begin{array}{l}\text { susumu } \\
\text { move forwar }\end{array}$ & \\
\hline "We go straig & into the futur & & \\
\hline $\begin{array}{l}\text { Example (9) zensya-ga } \\
\text { formar-Nom } \\
\text { kousya-ha } \\
\text { latter-Top }\end{array}$ & $\begin{array}{l}\text { kako-shika } \\
\text { past-only } \\
\text { mirai-he } \\
\text { future-to }\end{array}$ & $\begin{array}{l}\text { yume-mi-nai-noni } \\
\text { dream-see-neg-nominalizer } \\
\text { mukatte susun-deiru } \\
\text { toward move forward-non }\end{array}$ & $\begin{array}{l}\text { taishite, } \\
\text { against }\end{array}$ \\
\hline
\end{tabular}

In Examples (8)-(9), susumu (move forward) occurs in the context that shows "future growth" or "firm intention". In the data, five out of seven examples of Ego-moving susumu (move forward) arise in such a context. In contrast, Time-moving susumu (move forward) does not show such a constraint. The skewed frequencies of Time-moving and Ego-moving susumu reflect this disparity.

\section{Ground-Path Verbs}

This paper moves onto the next verb class: ground-path verbs. Ground-path verb is the largest verb class: It includes 23 verbs. About half of them are used metaphorically.

Table 3

Frequencies of Ground-Path Verbs in Each Temporal Metaphor ${ }^{3}$

\begin{tabular}{lcccc}
\hline & Time-moving & Ego-moving & Others and not decided & Sum \\
\hline sugiru "pass" & 357 & 55 & 39 & 451 \\
wataru "go across" & 0 & 0 & 228 & 228 \\
koeru "cross over" & 0 & 2 & 208 & 210 \\
chikadsuku "come close" & 45 & 1 & 2 & 48 \\
itaru "reach" & 2 & 0 & 9 & 11 \\
hairu "enter" & 0 & 0 & 8 & 8 \\
saru "leave" & 1 & 0 & 0 & 1 \\
syuppatsu-suru "start off" & 0 & 1 & 0 & 1 \\
hanareru "get away" & 0 & 1 & 0 & 1 \\
meguru "go around" & 0 & 0 & 1 & 1 \\
\hline Sum & 405 & 60 & 495 & 960 \\
\hline
\end{tabular}

As Table 3 shows, 10 verbs are used as metaphorical expressions of Time. Second, token frequencies of Time-moving metaphor and Ego-moving metaphor are 405 and $60(p=0.00, p<.01)$. Token frequency within each verb is totally skewed again. Among verbs in this verb class, sugiru (pass) is the only verb that has a high frequency of Ego-moving sense, although Time-moving sense is still dominant and Ego-moving sugiru (pass) has a constraint on its usage. Look at the following examples.

Time-moving sugiru (pass):

Example (10) yotei-jikan-ga sugi-ta

\footnotetext{
${ }^{3}$ A large number of Ego-observing metaphors are included in "others and not decided". Further studies are needed to clarify why this verb class has many Ego-observing expressions.
} 
schedule-time-Nom pass-pst

"Predetermined time was over."

$\begin{array}{rll}\text { Example (11) nagai } & \text { jikan-ga } & \text { sugi-ta } \\ \text { long } & \text { time-Nom } & \text { pass-pst } \\ & \text { "Long time has passed." }\end{array}$

Ego-moving sugiru (pass):

Example (10)' yotei-jikan-o $\quad$ sugi-temo, $\quad$ riku-ha $\quad$ mie-nai

schedule-time-Acc pass-though, land-Top see-Neg

"Though the arrival time has passed, we can't see the land yet."

Example (11)' *nagai jikan-o sugi-ta

long time-Acc pass-pst

The first noun is marked by the nominative marker "ga" in Time moving examples, (10) and (11), whereas it is marked by the accusative marker "o" in Ego-moving examples, (10)' and (11)'. Japanese can utilize sugiru (pass) in Ego-moving sense, shown in (10)', but only (11)' is not acceptable. Now, a question comes up: What yields the difference?

This disparity arises from the meaning of the co-occurring noun. In Examples (10) and (10)', sugiru (pass) co-occurs with the same noun yotei-jikan (predetermined time). On the other hand, sugiru (pass) co-occurs with nagai-jikan (long time) in Examples (11) and (11)'. In this case, yotei-jikan (predetermined time) shows a point on the time line. Videlicet, yotei-jikan (predetermined time) is a "Momentary Event". On the other hand, nagai-jikan (long time) means not "Momentary Event" but "Duration" of time. These examples show that Time-moving sugiru (pass) has both "Momentary Event" and "Duration" senses while Ego-moving sugiru (pass) only has "Momentary Event" sense. To put it another way, only Ego-moving sugiru (pass) has a constraint on its usage. This result parallels with the other results: Time-moving metaphor is more frequent in Japanese.

These results signal, in contrast with Lakoff and Johnson's suggestion about duality of Temporal metaphors, Time-moving metaphor and Ego-moving metaphor are not minimally differing variants of one another. Rather, each metaphor has its own constraints and set of component verbs in Japanese.

\section{Manner Verbs}

Finally, this paper argues the distributions of manner verbs (see Table 4).

Table 4

Frequencies of Manner Verbs in Each Temporal Metaphor

\begin{tabular}{lllll}
\hline & Time-moving & Ego-moving & Others and not decided & Sum \\
\hline nagareru "flow" & 182 & 1 & 7 & 190 \\
hashiru "run" & 1 & 4 & 1 & 6 \\
aruku "walk" & 1 & 3 & 0 & 4 \\
korogaru "roll" & 1 & 0 & 0 & 1 \\
tobu "fly" & 1 & 0 & 0 & 1 \\
\hline Sum & 186 & 8 & 8 & 202 \\
\hline
\end{tabular}

Table 4 shows that five verbs are used metaphorically among 13 manner verbs. Next, except for nagareru (flow), manner verbs are seldom used metaphorically. Although hashiru (run) and aruku (walk) are used six 
times and four times respectively, a few authors use these expressions several times. Further, some Japanese native speakers reply that Temporal metaphorical usages of manner verbs are highly figurative.

Among manner verbs, nagareru (flow) has remarkably large numbers of token frequency. Most Japanese compare the passage of time to the current of river. In fact, "jikan-ga nagareru" (Time flows) is one of the most natural expressions for the course of time. This shows the clear contrast with other manner verbs. The reason of this phenomenon may relate to an intrinsic uni-directionality of river current: "river flows gravitationally to the sea". In other words, it is likely that nagareru (flow) describes not only the manner of motion but also the direction of motion.

\section{General Result}

This paper has described the distributions of each motion verb class in Temporal metaphor one by one. Table 5 summarizes the type frequencies of motion verbs used in Temporal metaphorical usage.

Table 5

Summary: Motion Verbs Used in Metaphorical Usage

\begin{tabular}{llc}
\hline Verb type & Verbs & Total \\
\hline Path (direction) & iku (go), kuru (come), susumu (move forward), yatte-kuru (come) & 4 \\
Path (ground) & $\begin{array}{l}\text { koeru (cross over), wataru (go across), sugiru (pass), meguru (go around), hairu (enter), itaru } \\
\text { (reach), saru (leave), hanareru (get away), syuppatsu-suru (start off), chikadsuku (come close) }\end{array}$ & 10 \\
Manner verbs & aruku (walk), hashiru (run), korogaru (roll), tobu (fly), nagareru (flow) & 5 \\
\hline
\end{tabular}

These are the verbs that are used metaphorically in corpus data. As Table 1 and Table 5 show, less than half of motion verbs are used metaphorically. Apparently, this result conflicts with Özçalışkan's suggestion: Verb-framed languages utilize path verbs more often than manner verbs in metaphor. Notice, direction-path verbs include many verbs that describe vertical motion which is not used in temporal expressions. Moreover, the total type frequency of path verbs, 14 , is much more than that of manner verbs, five. This result supports the hypothesis Japanese uses path verbs metaphorically more often than manner verbs.

Then, Table 6 showes the summary of token frequencies of each temporal metaphor. Each number represents the number of metaphorical expressions of Time.

Table 6

Summary: Token Frequencies of Each Temporal Metaphor

\begin{tabular}{llccc}
\hline & Time-moving & Ego-moving & Others and not decided & Sum \\
\hline Path (direction) & 247 & 7 & 2 & 256 \\
Path (ground) & 405 & 60 & 495 & 960 \\
Manner & 186 & 8 & 8 & 202 \\
\hline Sum & 838 & 75 & 505 & 1418 \\
\hline
\end{tabular}

As Table 6 shows, corpus data include 1,418 metaphorical expressions in total. This work finds 838 Time-moving expressions while retrieving only 75 Ego-moving expressions. This observation indicates Time-moving metaphor is more frequent in Japanese $(p=0.00, p<.01)$. In addition, at each verb class, Time-moving metaphor is more frequently produced than Ego-moving metaphor. In summary, this tendency goes together with the hypothesis that Time-moving metaphor is more natural in Japanese than Ego-moving metaphor. Further, Japanese frequently utilizes path verbs in Time-moving sense. 


\section{Conclusion}

This paper conducted a corpus-based research on the distributions of dual Temporal metaphors. The author observed Time-moving metaphor is more frequent in Japanese, contrary to the researches in English and Chinese. Corpus data clearly showed that most motion verbs have skewed distributions between Time-Moving meaning and Ego-moving meaning; few verbs have "dual" usage at all in Japanese. What is more, data indicate Time-moving metaphor and Ego-moving metaphor are not mere a variant of each other, but each metaphor has peculiar and complicated constraints on its usage.

Several problems remain to be solved. First, other types of spatial expressions, other than motion verbs, need to be examined. Spatial configuration expressions such as front and back are the prime candidates among other spatial expressions. Second, describing Ego-observing metaphor is needed. Third, experimental studies are needed to reexamine results of this work. Preceding studies conducted experimental researches, so, experimental studies provide a fair comparison on this matter.

\section{References}

Evans, V. (Ed.). (2003). The structure of time: Language, meaning and temporal cognition. Amsterdam/Philadelphia: John Benjamins Publishing.

Gentner, D., Imai, M., \& Boroditsky, L. (2002). As time goes by: Evidence for two systems in processing space $\rightarrow$ time metaphors. Language and Cognitive Processes, 17(5), 537-565.

Kövecses, Z. (2002). Metaphor: A practical introduction. New York/Oxford: Oxford University Press.

Lakoff, G. (1993). The contemporary theory of metaphor. Metaphor and Thought, 2, 202-251.

Lakoff, G., \& Johnson, M. (1999). Philosophy in the flesh: The embodied mind and its challenge to western thought. New York: Basic books.

Matsumoto, Y. (1997). kuukan ido-no genngo hyogen-to sono kakucyo: ido doushi-ni okeru goika patan (Linguistic expressions of spatial motion and their extensions: Lexicalization patterns in motion verbs). In kuukan-to ido-no hyougen (Spacial expressions and motion expressions). Tokyo: kenkyusya syuppan.

May, H. M. H., \& Shelley, C. Y. H. (2007). Time-moving metaphors and ego-moving metaphors: Which is better comprehended by taiwanese?. Proceedings of the 21st Pacific Asia Conference on Language, Information, and Computation (pp. 173-181), Seoul, Korea.

Moore, K. E. (2000). Spatial experience and temporal metaphors in Wolof: Point of view, conceptual mapping, and linguistic practice (Doctoral dissertation). University of California, Berkeley.

Núñez, R. E., \& Sweetser, E. (2006). With the future behind them: Convergent evidence from Aymara language and gesture in the crosslinguistic comparison of spatial construals of time. Cognitive science, 30(3), 401-450.

Núñez, R. E., Motz, B. A., \& Teuscher, U. (2006). Time after time: The psychological reality of the ego-and time-reference-point distinction in metaphorical construals of time. Metaphor and Symbol, 21(3), 133-146.

Özçalışkan, Ş. (2003). Metaphorical motion in crosslinguistic perspective: A comparison of English and Turkish. Metaphor and Symbol, 18(3), 189-228.

Özçalışkan, Ş. (2004). Typological variation in encoding the manner, path, and ground components of a metaphorical motion event. Annual Review of Cognitive Linguistics, 2(1), 73-102.

Özçalışkan, Ş. (2005). Metaphor meets typology: Ways of moving metaphorically in English and Turkish. Cognitive Linguistics, 16(1), 207-246.

Özçalışkan, Ş. (2007). Metaphors we move by: Children's developing understanding of metaphorical motion in typologically distinct languages. Metaphor and Symbol, 22(2), 147-168.

Shinohara, K. (1999). Constraints on motion verbs in the TIME IS MOTION metaphor. Proceedings of the Annual Meeting of the Berkeley Linguistics Society, 25(1), 250-259.

Slobin, D. I. (2004). The many ways to search for a frog. In Relating events in narrative (Vol, 2, pp. 219-257). New York: Psychology Press.

Talmy, L. (1991). Path to realization: A typology of event conflation. Proceedings of the Annual Meeting of the Berkeley Linguistics Society, 17, 480-519. 